\title{
Laboratory X-ray Microscopy Study of Microcrack Evolution in a Novel Sodium Iron Titanate-Based Cathode Material for Li-Ion Batteries
}

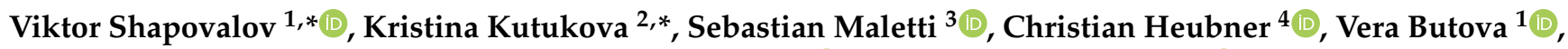 \\ Igor Shukaev ${ }^{5}$, Alexander Guda ${ }^{1}$, Alexander Soldatov ${ }^{1}$ (D) and Ehrenfried Zschech ${ }^{6}$ (D) \\ 1 The Smart Materials Research Institute, Southern Federal University, 178/24 A. Sladkova Street, \\ 344090 Rostov-on-Don, Russia; vbutova@sfedu.ru (V.B.); guda@sfedu.ru (A.G.); soldatov@sfedu.ru (A.S.) \\ 2 Fraunhofer Institute for Ceramic Technologies and Systems IKTS, Maria-Reiche-Street 2, \\ 01109 Dresden, Germany \\ 3 Fraunhofer Institute for Ceramic Technologies and Systems IKTS, Winterbergstraße 28, \\ 01277 Dresden, Germany; sebastian.maletti@ikts-extern.fraunhofer.de \\ 4 Institute of Materials Science, TU Dresden, 01062 Dresden, Germany; christian.heubner@ikts.fraunhofer.de \\ 5 Department of Chemistry, Southern Federal University, 7 Zorge Street, 344090 Rostov-on-Don, Russia; \\ ishukaev@sfedu.ru \\ 6 deepXscan $\mathrm{GmbH}$, Research and Innovation, Zeppelinstrasse, 01324 Dresden, Germany; \\ ehrenfried.zschech@deepxscan.com \\ * Correspondence: viks@sfedu.ru (V.S.); kristina.kutukova@ikts.fraunhofer.de (K.K.)
}

check for updates

Citation: Shapovalov, V.; Kutukova, K.; Maletti, S.; Heubner, C.; Butova,

V.; Shukaev, I.; Guda, A.; Soldatov, A.;

Zschech, E. Laboratory X-ray

Microscopy Study of Microcrack Evolution in a Novel Sodium Iron Titanate-Based Cathode Material for Li-Ion Batteries. Crystals 2022, 12, 3 .

https://doi.org/10.3390/

cryst12010003

Academic Editors:

Kahraman Keskinbora, Umut T. Sanli and Sebastian Wintz

Received: 26 November 2021

Accepted: 17 December 2021

Published: 21 December 2021

Publisher's Note: MDPI stays neutral with regard to jurisdictional claims in published maps and institutional affiliations.

Copyright: (C) 2021 by the authors. Licensee MDPI, Basel, Switzerland. This article is an open access article distributed under the terms and conditions of the Creative Commons Attribution (CC BY) license (https:// creativecommons.org/licenses/by/ $4.0 /)$.

\begin{abstract}
The long-term performance of batteries depends strongly on the 3D morphology of electrode materials. Morphological changes, i.e., particle fracture and surface deterioration, are among the most prominent sources of electrode degradation. A profound understanding of the fracture mechanics of electrode materials in micro- and nanoscale dimensions requires the use of advanced in situ and operando techniques. In this paper, we demonstrate the capabilities of laboratory X-ray microscopy and nano X-ray computed tomography (nano-XCT) for the non-destructive study of the electrode material's 3D morphology and defects, such as microcracks, at sub-micron resolution. We investigate the morphology of $\mathrm{Na}_{0.9} \mathrm{Fe}_{0.45} \mathrm{Ti}_{1.55} \mathrm{O}_{4}$ sodium iron titanate (NFTO) cathode material in Li-ion batteries using laboratory-based in situ and operando X-ray microscopy. The impact of the morphology on the degradation of battery materials, particularly the size- and density-dependence of the fracture behavior of the particles, is revealed based on a semi-quantitative analysis of the formation and propagation of microcracks in particles. Finally, we discuss design concepts of the operando cells for the study of electrochemical processes.
\end{abstract}

Keywords: battery; cathode material; operando study; X-ray microscopy; X-ray computed tomography; 3D imaging; crack formation; crack propagation; degradation process

\section{Introduction}

The development of new materials for efficient and durable systems used for energy storage and conversion is crucial for modern and future energy technologies and transport, which heavily rely on the use of renewable power sources, hybrid, and all-electric vehicles [1-3]. The performance of batteries strongly depends on the 3D microstructure and morphology of the porous electrode materials [4,5]. The morphology and the fluid dynamic transport properties of such porous structures are described by open porosity, pore size distribution, permeability, tortuosity, and constrictivity [6-8]. One of the main concerns related to alkali metal-ion batteries is their lifetime extension, as recycling technologies are only in the early development stage and are far from economically efficient [9-11].

Morphological changes, i.e., particle fracture and surface deterioration, are among the most prominent sources of electrode degradation and eventual irreversible capacity loss $[12,13]$. These effects play a major role in electrode failure at high current loads, 
especially in materials where the reversible storage of alkali ions is accompanied by high volume changes [14]. Microcrack formation and propagation in particles that form the electrodes lead to rupture and reformation of the solid electrolyte interphase (SEI), which is accompanied by a capacity decline in full cells. Furthermore, microcracks cause a decrease in electronic conductivity, as well as a disruption of ionic transport [12,15]. Electrically disconnected particles and accelerating chemical reactions caused by the newly formed SEI result in increased impedance and reduced battery performance.

Therefore, a profound understanding of the fracture mechanics of electrode materials in micro- and nanoscale dimensions, including the formation and propagation of microcracks, is mandatory for the development of more stable and durable electrodes that meet the lifetime requirements for specific use cases. Only in situ and operando studies at conditions as close as possible to the real operational conditions of the system allow the study of the degradation kinetics and provide reliable data on the operation of battery electrodes during real electrochemical processes [16-18]. These in situ and operando regimes allow the investigation of physical and chemical transformations of the material in a time-resolved manner and the tracking of intermediate states. In addition, numerous factors that might heavily affect the accuracy and the reproducibility of the data and eventually the final result of an experimental study, such as electrode relaxation upon removal of the potential, sample contamination and degradation during the transfer from the electrochemical cell to the experimental setup, as well as sample preparation procedures, are reduced in electrochemical operando studies [19-22].

Experiments that monitor the behavior of a material during the charge/discharge cycles of a battery require the use of advanced techniques and tools for in situ and operando studies. In particular, an experimental setup is needed for microcrack formation and growth during charge/discharge cycling of the battery cell and for simultaneous imaging of microcracks in battery materials at the micro- and nanoscale. X-ray imaging techniques have the particular advantage of allowing non-destructive 3D imaging of the interior of opaque materials, which is a necessary prerequisite for the study of kinetic processes and the development of the microstructure in materials and systems [23-25].

A miniaturized test setup for 3D-structured systems and materials-an electrochemical cell in an X-ray microscope-provides a unique capability for high-resolution 3D imaging of microcracks during cycling the battery cell. Nano-X-ray computed tomography (nano$\mathrm{XCT}$ ) is suitable for imaging microcracks in advanced materials for battery electrodes with sub-100 nm resolution and to draw conclusions on the mechanical robustness of the battery cell itself. X-ray microscopy and nano-XCT are the only techniques that allow the nondestructive imaging of microcracks at sub-micron resolution [26].

The potential of X-ray microscopy and nano-XCT for battery research has been reported in several studies at synchrotron beamlines [27-30]. However, systematic material development requires an experimental setup next to the material synthesis and 24/7 tool access. Therefore, in this paper, we demonstrate the capabilities of laboratory nano-XCT for the study of the 3D morphology of electrode materials and defects, such as microcracks.

In recent years, increasing efforts have been devoted to the development of hybrid $\mathrm{Li} / \mathrm{Na}$-ion systems, motivated mainly by the higher abundance and lower cost of $\mathrm{Na}[31,32]$. Such systems may be based on polycationic electrode materials or on Li-based (Na-based) electrodes or electrolyte in Na-based (Li-based) electrochemical systems [33]. Furthermore, the employment of materials with mixed d-metal cations or materials that exhibit anion redox reactions, such as oxygen redox, has recently been studied intensively. In this scope and due to the abundant nature of Ti, pure titanate-based or Ti-doped polyanionic cathodes are receiving ever-increasing attention [34].

Prospective candidates for both $\mathrm{Li}$ - and Na-ion systems are novel cathode materials based on $\mathrm{Na}_{0.9} \mathrm{Fe}_{0.45} \mathrm{Ti}_{1.55} \mathrm{O}_{4}$ sodium iron titanate (NFTO) [35]. Although the material demonstrates promising electrochemical performance and a potential for reversible anion (oxygen) redox activity, it suffers from the irreversible capacity loss of around $20 \%$ in the first three cycles for Li-ion systems [36]. One of the potential reasons is the degradation of the 
active phase material, which leads to a disruption of the transport of charge carriers, i.e., ions and electrons. In this paper, we investigate the morphological aspects of material stability in Li-ion batteries by means of laboratory-based in situ and operando X-ray microscopy.

\section{Materials and Methods}

Laboratory X-ray microscopy data were acquired using an Xradia nanoXCT-100 (Xradia, Pleasanton, CA, USA) tool. This transmission X-ray microscope (TXM) consists of a rotating anode $\mathrm{X}$-ray source $(\mathrm{Cu}-\mathrm{K} \alpha$ radiation, $8 \mathrm{keV}$ photon energy), capillary condenser optics with a central beam stop, a Fresnel zone plate (FZP) as an objective lens, and a $2 \mathrm{D}$ detector $(1024 \times 1024$ pixels). In the full-field imaging mode, the field of view is $67 \mu \mathrm{m} \times 67 \mu \mathrm{m}$, resulting in a pixel size of $65 \mathrm{~nm}$. Since this setup provides almost parallel-beam geometry, rotation of 180 degrees is sufficient for tomography. Imaging microcrack evolution in 3D nanopatterned systems using a laboratory X-ray microscope equipped with a micro-mechanical stage has been shown recently [37,38]. In this study, a specially designed electrochemical operando cell is built and applied for the imaging of morphology changes and of the evolution of defects such as microcracks in particles. In order to collect tomography data and to meet the requirements for the microscope setup (working distance, focus, field of view, system rigidity), the cell is attached to the rotary stage inside the microscope.

The electrochemical operando cell (Figure 1a) consists of two Sigradur-G glassy carbon discs (Hochtemperatur-Werkstoffe $\mathrm{GmbH}$, Thierhaupten, Germany), which act as current collectors and X-ray-transparent windows. The $300 \mu \mathrm{m}$ thick discs are housed in the recesses of stainless steel plates to increase the structural integrity of the electrochemical operando cell and to provide reliable and convenient electrical contacts to the glassy carbon discs. Anode and cathode sides of the cell are separated by an electrically insulating 3Dprinted polyamide (Nylon Strong, Print Product, Moscow, Russia) spacer that also centers the sealing O-ring (EPDM rubber, Marco Rubber \& Plastics, Seabrook, NH, USA). This ensures its optimal compression for proper sealing while providing additional stiffness to the cell. The cell is fixed and tightened with 4 bolts that are insulated from the cell with 3D-printed polyamide liners (same material as for spacer). After assembly, the cell is installed into the custom adapter and mounted to the standard sample plate inside the X-ray microscope (Figure 1b). The adapter ensures proper cell alignment and a reliable connection of wires with circular terminals to the stainless steel plates. Slits in the stainless steel plates and the low total thickness of the cell internals $(\sim 1.4 \mathrm{~mm}$ between outer surfaces of the glassy carbon windows) allow X-rays to pass through the electrochemical operando cell at a wide range of angles, from -67.5 to 67.5 degrees relative to the normal, enabling limited-angle X-ray tomography. The angular range is limited due to the cell design, as the cell enclosure and internal components block the beam at higher angles.

The $\mathrm{Na}_{0.9} \mathrm{Fe}_{0.45} \mathrm{Ti}_{1.55} \mathrm{O}_{4}$ active material, synthesized as reported elsewhere [35], was mixed and mortared with carbon (Timcal Super P Conductive, Alfa Aesar, Haverhill, MA, USA) and PVDF (Sigma Aldrich, St. Louis, MO, USA, 5\% solution in NMP) in a 70:25:5 wt.\% ratio, with an additional $40 \mathrm{wt}$ \% (relative to the total mass of the mixture) of pure NMP (Sigma Aldrich) added afterwards to reach the viscosity required for electrode deposition. The resulting slurry was cast onto glassy carbon disks to form electrodes ( $5 \mathrm{~mm}$ in diameter) with a mass load of $\sim 5 \mathrm{mg} / \mathrm{cm}^{2}$. The mass load was calculated to achieve $\sim 15 \mu \mathrm{m}$ electrode thickness to be transparent for $8 \mathrm{keV}$ photons. Gold beads (1.5-3 $\mu \mathrm{m}$ size, Alfa Aesar) were deposited on the surface of the slurry to act as markers for the 3D tomographic reconstruction. All preparations were performed in a glovebox under an Ar atmosphere. Electrodes were then dried at $80{ }^{\circ} \mathrm{C}$ under vacuum for $12 \mathrm{~h}$. 

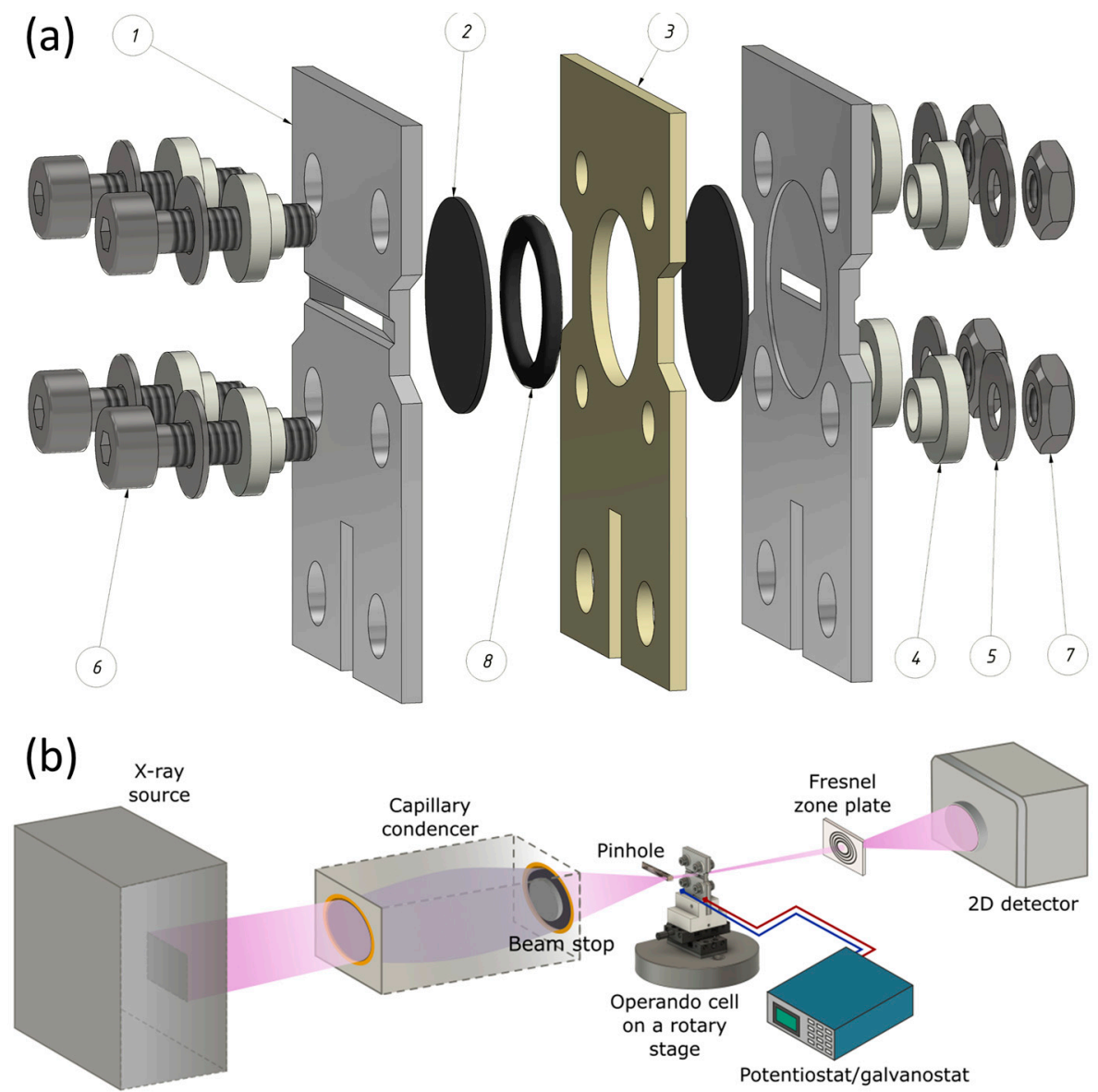

Figure 1. (a) Schematic representation of the electrochemical operando cell, including: (1) stainless steel enclosure plate, (2) glassy carbon window/current collector, (3) polyamide spacer, (4) polyamide insulator, (5) washer, (6) bolt, (7) nut, (8) sealing O-ring; (b) schematic representation of the laboratory experimental setup for electrochemical in situ and operando nano-XCT studies.

Electrochemical studies were carried out in half cells against a metallic Li foil (3 layers, G-Materials, Germany, $250 \mu \mathrm{m}$ thickness) using a SP200 potentiostat/galvanostat (Biologic Instruments, Cecinet Parise, France). A Celgard 2600 polymer separator (Celgard, Charlotte, NC, USA) soaked with 1M LiPF6 in EC:DMC 1:1 ( $v / v$, battery grade, Sigma Aldrich) was applied. The assembly process was performed in a glovebox under an Ar atmosphere. For operando X-ray radiography, the cells were cycled galvanostatically using a current density of $60 \mathrm{~mA} / \mathrm{g}$ between $1.5 \mathrm{~V}$ and $4.5 \mathrm{~V}$ vs. $\mathrm{Li} / \mathrm{Li}^{+}$. For in situ X-ray tomography in either fully charged or discharged states, a potentiostatic hold period of $20.5 \mathrm{~h}$ was introduced at the upper and lower cut-off voltages (see Figure 2).

An X-ray tomography tilt series consisting of 601 images within a limited angular range of $135^{\circ}$ was recorded at several electrochemical stages of the kinetic process, i.e., the charging/discharging cycles of the battery. The exposure time per image was $120 \mathrm{~s}$. The camera binning of 2 resulted in a voxel size of $129 \mathrm{~nm}^{3}$.

The crack width (distance between the particles) was analyzed using the virtual projections with the "Line Width" tool of ImageJ software [39]. The data were taken at the center of the particle and presented as measurements from the same area in three directions. 


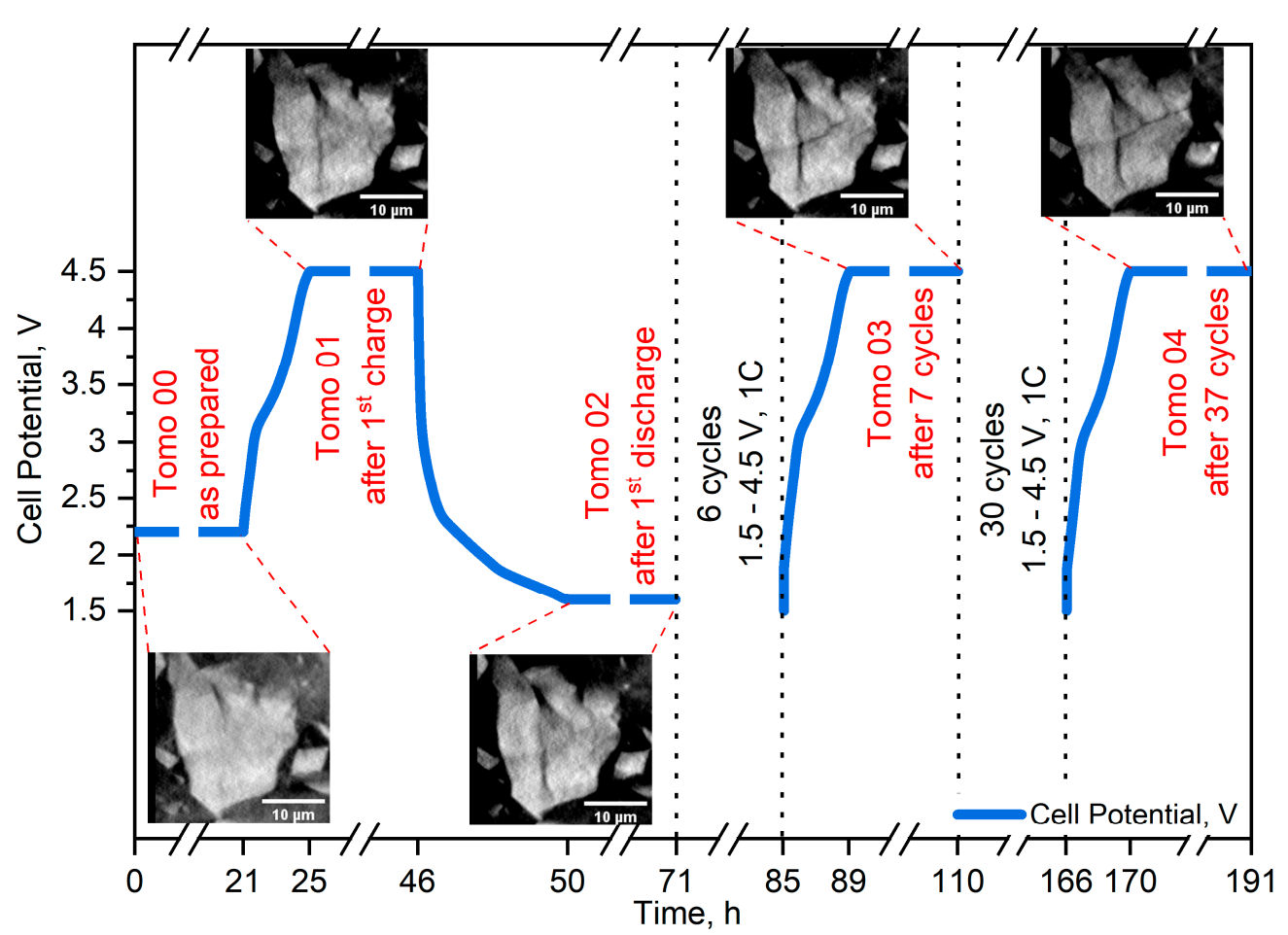

Figure 2. Electrochemical cell potential as a function of time, with "stopping points" for X-ray tomography studies denoted. Insets show characteristic virtual cross-sections. Only the first cycle and two further "stopping points" with virtual cross-sections are shown; the rest of the electrochemical process is represented as gaps.

\section{Results}

The evolution of a specific microcrack in a selected particle due to cycling is shown in a sequence of virtual cross-sections at specific electrochemical stages in Figure 3. It is presented by reconstructed of single cross-section images for three planes $X Y, Y Z$, and XZ (Cartesian coordinate system) from the initial (Tomo 00) to the final (Tomo 04) electrochemical states. In the $X Y$ and $X Z$ cross-sections at Tomo 00 , the initial microcrack, visible as a dark line on a bright dense particle, is more pronounced than in the $Y Z$ plane. The microcrack growth is already visible in all space dimensions at the first charge (Tomo 01) and first discharge (Tomo 02) stages. Further charging/discharging for five cycles (Tomo 03) and 30 cycles (Tomo 04) results in the separation of the large solid particle into smaller ones. The semi-quantitative investigation of the crack width growth in different projection planes is presented in Figure 4. Based on these data, we are able to conclude that the microcrack growth is similar in all three Cartesian directions, and that after six cycles microcracks begin to split some large particles of the NFTO cathode into smaller particles. A more detailed qualitative and quantitative analysis is planned using algorithms to compensate for inaccuracies in the reconstruction of high-resolution XCT data, as described in [40]. 


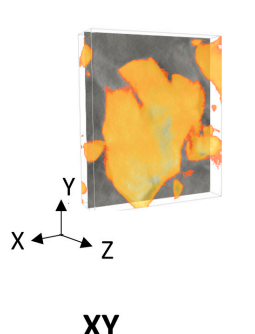

Slice \#325

YZ

Slice \#341

$\mathbf{X Z}$

Slice \#106
Tomo 00
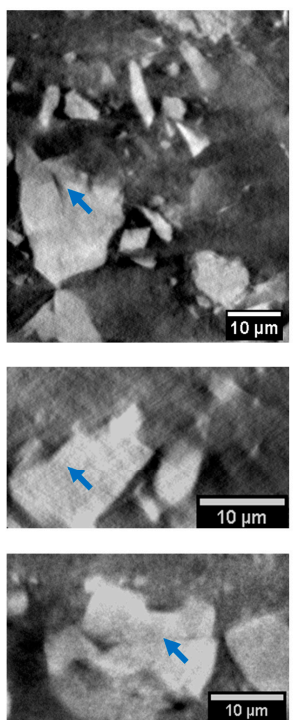

Tomo 01
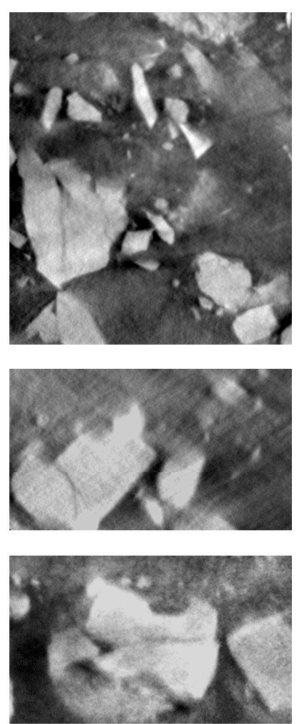

Tomo 02
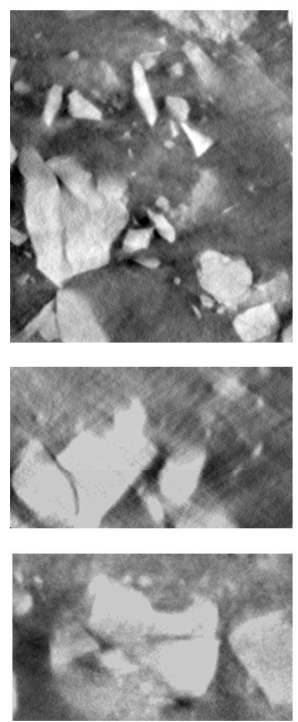

Tomo 03
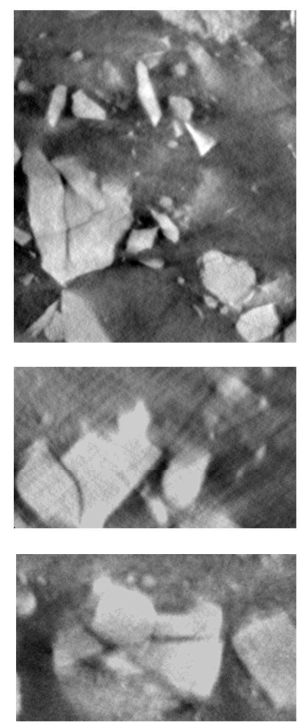

Tomo 04
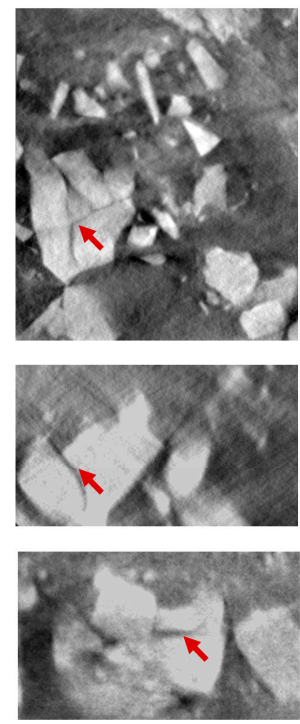

Figure 3. X-ray tomography cross-sections showing the microcrack formation and growth process in one of the damaged particles. Cracks that are (semi)quantitatively analyzed on Figure 4 are marked with arrows. The blue arrow shows the initial state of the crack, and the red arrow shows the final state.

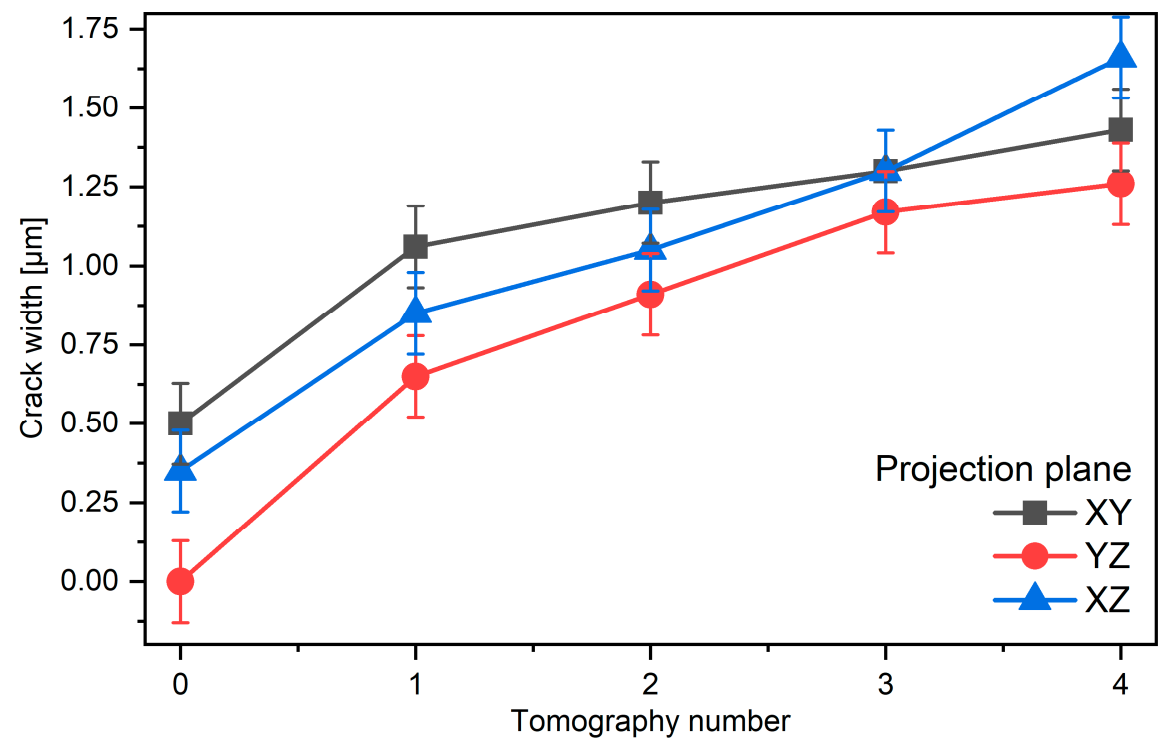

Figure 4. Evolution of microcracks in the particle marked in Figure 3. Growth of the most pronounced cracks in three different virtual cross-sections is shown as a function of tomography number. The error bar corresponds to the voxel size of $129 \mathrm{~nm}^{3}$.

The X-ray tomography data show the presence of particles with different densities and size distribution. Many particles in the as-prepared material already demonstrate some initial microcracks. However, most of them do not show any noticeable growth during cycling. Another notable observation is that the probability of the formation and growth of microcracks is higher for larger particles with low density than for the denser and finer particles. These phenomena are indicated in Figure 5, which shows a few more medium-sized particles with chipped cracks (red arrows) that do not propagate due to cycling, and denser particles without visible cracks (red square). 


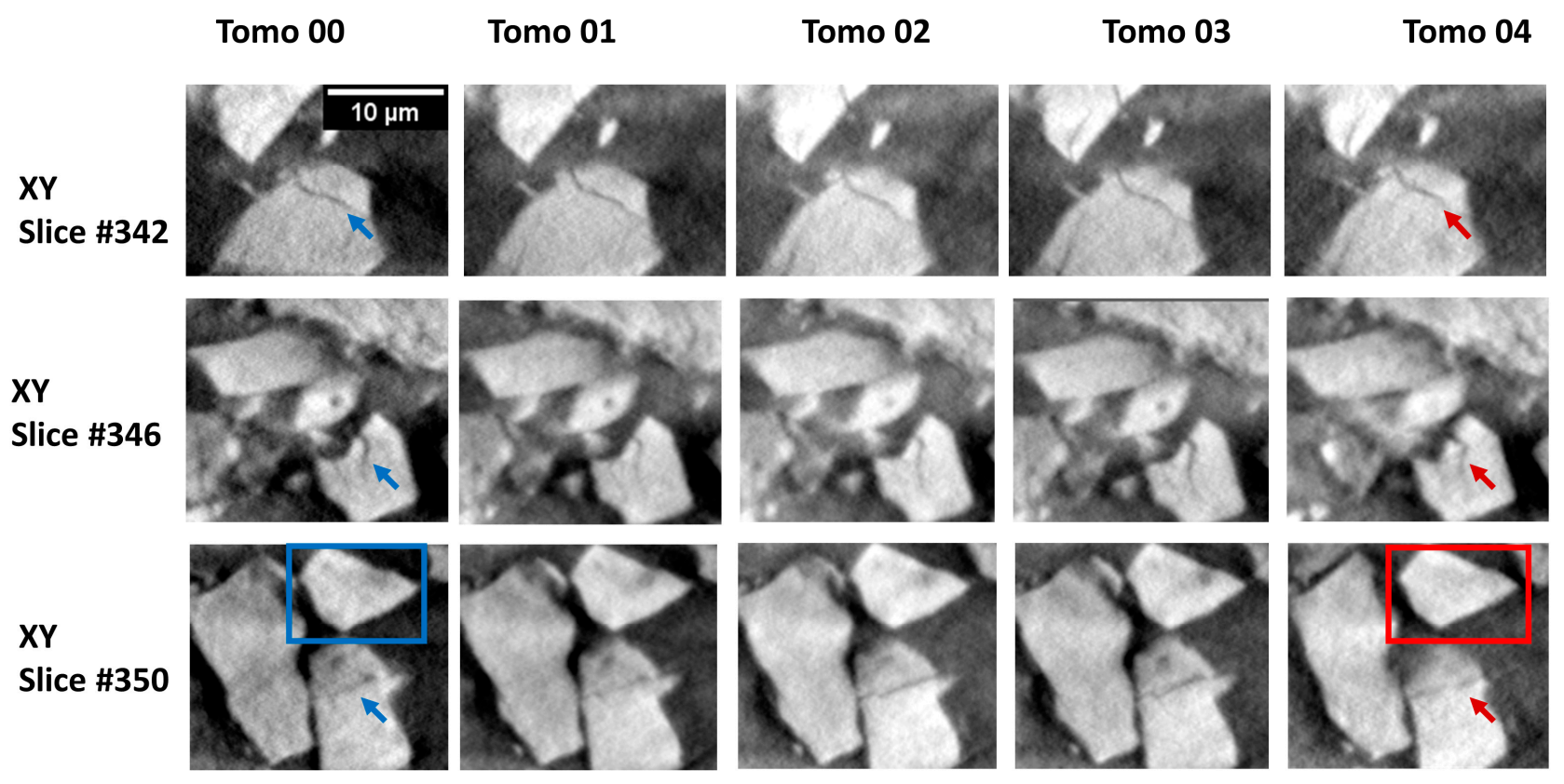

Figure 5. Virtual X-ray tomography cross-sections. Arrows mark medium-sized and less dense particles that already had microcracks in the as-prepared material, but did not show any evolution. Rectangles mark a smaller, dense particle that did not show any cracks during the experiment.

\section{Discussion}

It is widely accepted that fracture in battery materials is one of the primary sources of electrode degradation and capacity loss [41]. The rapid occurrence and development of microcracks during the very first cycles, observed for the NFTO material in this study, are supposed to be the reason for the previously observed capacity loss of around $20 \%$ in the first three cycles, accompanied by a decrease in the $\mathrm{Fe}^{2+} / \mathrm{Fe}^{3+}$ redox conversion ratio [36]. Since the TEM investigation suggests an average particle size of 2-6 $\mu \mathrm{m}$ for the as-prepared $\mathrm{Na}_{0.9} \mathrm{Fe}_{0.45} \mathrm{Ti}_{1.55} \mathrm{O}_{4}$ active material, we are obviously dealing with secondary particles, namely agglomerates of primary particles with carbon and binder polymer [35]. Thus, for the particles that are denser (as judged by the gray value), we assume more rugged and condensed secondary particles (i.e., containing more active phase) rather than those of the NFTO phase. The intergranular fracture (cracking of secondary electrode particles) often leads to the isolation of active material. Hence, it might no longer be accessible for the transport of charge carriers, such as ions or electrons, and therefore becomes electrochemically inactive. Microcrack growth and further separation of particles also continuously create new interfaces that provokes unwanted SEI formation, consumption of electrolyte, active electrode material, and alkali metal ions, and eventually decreases the cycling efficiency and reduces the lifetime of the battery cell.

Chemo-mechanical stress caused by the supposed electrochemical substitution of $\mathrm{Na}$ by Li ions during the initial cycles of NFTO material in the Li-ion system might accelerate the processes of microcrack formation and propagation. The estimated volume change between the fully charged and discharged states of the material should be around $2 \%$, as suggested by the results of DFT geometry optimization for the NFTO structure (refined from powder XRD data) with different contents of $\mathrm{Li}$ and $\mathrm{Na}$ ions [36]. At the same time, some of the particles of the as-prepared electrode already had pre-cracks, either as a result of the applied synthesis technique or due to mechanical impact during the electrode slurry preparation. Although there are several studies suggesting that particles with initial defects are more likely to show further fracture development, in the present case, not all were susceptible to the crack evolution [42-44]. Moreover, there is a clear relationship between particle size and crack formation. Larger and less dense particles are more susceptible to 
both initial fracture and further degradation. This phenomenon of particle size-dependence on fracture was previously reported for other insertion cathode materials $[14,45]$.

A possible reason for the higher fracture susceptibility of larger particles (especially at higher current densities) might be the state-of-charge (SOC) heterogeneity. For materials with slower insertion kinetics, the alkali metal ion concentration and thus the local charge state of a redox-active transition metal might differ substantially between the core and the shell of the particle, with the difference increasing as the particle size and current density increased $[14,46,47]$. In addition, gradients of the chemical potential or the concentration of elements in a (large) particle might significantly accelerate the intragranular fracture processes $[13,48]$. However, to address the SOC heterogeneity in the particles, the $3 \mathrm{~d}$-metal charge state has to be quantified in a spatially resolved manner by applying high-resolution spectroscopic techniques such as X-ray absorption spectromicroscopy or spectrotomography [49-51]. Although it is not possible with state-of-the-art laboratory nano-XCT tools because of the use of characteristic $\mathrm{X}$-rays $(\mathrm{Cu}-\mathrm{K} \alpha)$, the developed electrochemical operando cell is well suited to $\mathrm{X}$-ray absorption spectroscopy studies.

One key element of operando studies of batteries and their components is the design of the electrochemical operando cell [52]. For neutron or ultrahard X-ray studies, it is possible to use simple pouch cells without any windows; for X-ray techniques using photon energies below $10 \mathrm{keV}$, the cell design has to include $\mathrm{X}$-ray transparent windows [53]. For laboratory nano-XCT tools, the selection of the material for the windows is particularly important because of the lower brilliance of the X-ray sources compared to synchrotron radiation sources. A large variety of window materials that was previously employed in cell designs. One class of materials is polymer thin films, such as polyimide (Kapton) or polyester (Mylar) [54,55]. However, these electrically insulating materials introduce current inhomogeneities, since the composite electrode itself usually exhibits comparably low electron conductivity. This could result in reduced electrochemical activity in the window region, the region of interest for the experiment. The use of electrodes pre-deposited on some conductive surface (i.e., $\mathrm{Al}$ or $\mathrm{Cu}$ foil) will eliminate this issue; however, the metal foils will introduce additional absorption background for the acquired X-ray images. The reduced signal-to-noise ratio will require increased acquisition times. As an alternative, polymer films might be coated e.g., with a thin layer of aluminum to provide a homogeneous current density across the whole surface of the electrode [56]. However, the gas and moisture permeability of these thin films limits the overall lifetime of the electrochemical cells. Moreover, polymer thin films are not rigid enough to ensure proper pressure on the electrode stack. This, again, will negatively affect the reliability of the electrical contact and the electrochemical behavior of the cell, especially at high current densities. To overcome this issue, one could use structurally rigid X-ray-transparent materials, such as mica or sapphire [57]. However, these materials are also electrically insulating and require the use of conductive coatings or dedicated current collectors. Additionally, highly textured or polycrystalline windows might introduce additional features to the images. Beryllium, the most commonly used material for X-ray windows, aside from being highly toxic, is easily oxidized and unstable at high electrode potentials $\left(>4 \mathrm{~V} \mathrm{vs.} \mathrm{Li} / \mathrm{Li}^{+}\right)$.

Ideally, the windows for an electrochemical operando cell must be rigid, nonpermeable to gases and moisture, and electrically conductive. In addition, it should also be amorphous and should have a low absorption of photons in the selected energy range [58]. Glassy carbon, used in a wide variety of electrochemical and electrocatalytic applications, fulfils these requirements. Due to being both highly conductive and X-ray transparent, it acts simultaneously as a current collector and a window. Its high density provides a reliable seal for the electrode stack, protecting the cell from damage by gases and moisture. Though somewhat sensitive to direct contact with lithium and sodium, glassy carbon has negligible electrochemical activity over a wide potential range from 0.5 to $4.8 \mathrm{~V} \mathrm{vs}$. $\mathrm{Li} / \mathrm{Li}^{+}$. Thus, it is suitable for applications with most electrode compositions for $\mathrm{Li}$ - and $\mathrm{Na}$-ion batteries. However, for operando studies at laboratory tools, the windows should be comparably thin due to the limited brilliance of the X-ray source. Such thin glassy carbon windows are 
extremely fragile and require proper structural support from the cell enclosure. Additionally, the overall thickness of the cell should be as low as possible, since the pathway of the $\mathrm{X}$-ray beam through the window material increases significantly at the high angles needed for nano-XCT image acquisition (or spectrotomography). All these factors were considered during the design and the development of the electrochemical operando cell described in this paper.

\section{Conclusions}

The application of operando X-ray imaging with a properly designed electrochemical cell in battery research enables the 3D visualization of the microstructure and morphology evolution of composite electrodes, e.g., the formation and growth of defects, such as microcracks. In addition, operando studies provide numerous benefits in terms of reliability and reproducibility of the measurements. Easy and safe electrode preparation techniques, similar to the ones used for conventional electrochemical measurements in Swagelok-type cells or coin cells, can be applied. The operando approach eliminates the risk of chemical or mechanical damage to the material during sample preparation and provides the possibility to track intermediate states. Data from the same region of interest of the same sample can be gathered continuously, allowing the tracking of the full evolution of specific microstructure features and defects. The application of high-resolution operando X-ray imaging together with complementary techniques (i.e., X-ray absorption spectroscopy for spectromicroscopy or spectrotomography) would allow complex data on both morphological and chemical states of the materials to be gathered.

The combination of the operando approach and high-resolution X-ray imaging opens the way for the development of design concepts for novel engineered material systems such as battery electrodes, considering their local mechanical properties. The approach described in this paper is extendable to other materials for energy storage and conversion (e.g., materials for fuel cells and water splitting) and more generally to all materials, particularly to composites and skeleton materials, and to hierarchically structured material systems.

Using a laboratory $\mathrm{X}$-ray microscope equipped with an electrochemical operando cell on a rotary stage, it is possible to reconstruct the 3D morphology evolution of electrode materials. The approach allows tracking of the formation and propagation of microcracks in the active phase down to a single particle semi-quantitatively. The data obtained provide morphological insights on material performance and degradation, as well as the sizeand density-dependence of the fracture behavior. The electrochemical operando cell has the design and the features suitable for integration into various complementary $\mathrm{X}$-ray spectroscopy and X-ray scattering experiments to allow the kinetic studies of the atomic and electronic structures of the sample.

Based on the understanding of kinetic processes in materials, such as changes in their morphology (e.g., volume change caused by phase transformations) and the formation and growth of defects (e.g., microcracks), concepts for crack steering into regions of high fracture toughness can be established with the goal of designing engineered damagetolerant materials.

Author Contributions: Conceptualization, E.Z., K.K. and V.S.; Methodology, E.Z., K.K., A.G. and V.S.; Validation, E.Z.; Formal analysis, V.S., K.K. and S.M.; Investigation, V.S., K.K. and S.M.; Resources, E.Z., S.M., C.H., V.B. and I.S.; Data curation, K.K., S.M. and V.S.; Writing-original draft preparation, V.S., K.K. and E.Z.; Writing - review and editing, A.G., S.M., C.H., V.B. and I.S.; Visualization, V.S. and K.K.; Supervision, E.Z., A.G. and A.S.; Project administration, E.Z.; Funding acquisition, E.Z. All authors have read and agreed to the published version of the manuscript.

Funding: The work was financially supported by the Ministry of Science and Higher Education of the Russian Federation (State assignment in the field of scientific activity, № 0852-2020-0019).

Data Availability Statement: The data presented in this study are available on request from the corresponding authors. This data is not publicly available due to excessive size and complexity of structuring. 


\begin{abstract}
Acknowledgments: V.S. would like to acknowledge the financial support of his research internship at Fraunhofer Institute for Ceramic Technologies and Systems in Dresden, Germany, provided by the Ministry of Science and Higher Education of the Russian Federation in the framework of a scholarship of the President of the Russian Federation to study abroad during 2020/2021 academic year.

Conflicts of Interest: The authors declare no conflict of interest. The funders had no role in the design of the study; in the collection, analyses, or interpretation of data; in the writing of the manuscript, or in the decision to publish the results.
\end{abstract}

\title{
References
}

1. Nadeem, F.; Hussain, S.M.S.; Tiwari, P.K.; Goswami, A.K.; Ustun, T.S. Comparative Review of Energy Storage Systems, Their Roles, and Impacts on Future Power Systems. IEEE Access 2019, 7, 4555-4585. [CrossRef]

2. Yuan, Y.; Lu, J. Demanding energy from carbon. Carbon Energy 2019, 1, 8-12. [CrossRef]

3. Cano, Z.P.; Banham, D.; Ye, S.; Hintennach, A.; Lu, J.; Fowler, M.; Chen, Z. Batteries and fuel cells for emerging electric vehicle markets. Nat. Energy 2018, 3, 279. [CrossRef]

4. Heubner, C.; Nikolowski, K.; Reuber, S.; Schneider, M.; Wolter, M.; Michaelis, A. Recent Insights into Rate Performance Limitations of Li-ion Batteries. Batter. Supercaps 2021, 4, 268-285. [CrossRef]

5. De Biasi, L.; Schwarz, B.; Brezesinski, T.; Hartmann, P.; Janek, J.; Ehrenberg, H. Chemical, Structural, and Electronic Aspects of Formation and Degradation Behavior on Different Length Scales of Ni-Rich NCM and Li-Rich HE-NCM Cathode Materials in Li-Ion Batteries. Adv. Mater. 2019, 31, 1900985. [CrossRef] [PubMed]

6. Bini, F.; Pica, A.; Marinozzi, A.; Marinozzi, F. A 3D Model of the Effect of Tortuosity and Constrictivity on the Diffusion in Mineralized Collagen Fibril. Sci. Rep. 2019, 9, 2658. [CrossRef] [PubMed]

7. Zhang, Z.; Jones, D.; Yue, S.; Lee, P.D.; Jones, J.R.; Sutcliffe, C.J.; Jones, E. Hierarchical tailoring of strut architecture to control permeability of additive manufactured titanium implants. Mater. Sci. Eng. C 2013, 33, 4055-4062. [CrossRef] [PubMed]

8. Sun, G.; Zhang, Y.; Sun, W.; Liu, Z.; Wang, C. Multi-scale prediction of the effective chloride diffusion coefficient of concrete. Constr. Build. Mater. 2011, 25, 3820-3831. [CrossRef]

9. $\quad$ Fan, E.; Li, L.; Wang, Z.; Lin, J.; Huang, Y.; Yao, Y.; Chen, R.; Wu, F. Sustainable Recycling Technology for Li-Ion Batteries and Beyond: Challenges and Future Prospects. Chem. Rev. 2020, 120, 7020-7063. [CrossRef] [PubMed]

10. Larouche, F.; Tedjar, F.; Amouzegar, K.; Houlachi, G.; Bouchard, P.; Demopoulos, G.P.; Zaghib, K. Progress and Status of Hydrometallurgical and Direct Recycling of Li-Ion Batteries and Beyond. Materials 2020, 13, 801. [CrossRef]

11. Zhou, L.-F.; Yang, D.; Du, T.; Gong, H.; Luo, W.-B. The Current Process for the Recycling of Spent Lithium Ion Batteries. Front. Chem. 2020, 8, 578044. [CrossRef]

12. Kim, N.Y.; Yim, T.; Song, J.H.; Yu, J.-S.; Lee, Z. Microstructural study on degradation mechanism of layered LiNi0.6Co0.2Mn0.2O2 cathode materials by analytical transmission electron microscopy. J. Power Sources 2016, 307, 641-648. [CrossRef]

13. Zheng, J.; Gu, M.; Xiao, J.; Zuo, P.; Wang, C.; Zhang, J.-G. Corrosion/Fragmentation of Layered Composite Cathode and Related Capacity/Voltage Fading during Cycling Process. Nano Lett. 2013, 13, 3824-3830. [CrossRef]

14. Xia, S.; Mu, L.; Xu, Z.; Wang, J.; Wei, C.; Liu, L.; Pianetta, P.; Zhao, K.; Yu, X.; Lin, F.; et al. Chemomechanical interplay of layered cathode materials undergoing fast charging in lithium batteries. Nano Energy 2018, 53, 753-762. [CrossRef]

15. Erickson, E.M.; Schipper, F.; Penki, T.R.; Shin, J.-Y.; Erk, C.; Chesneau, F.-F.; Markovsky, B.; Aurbach, D. Review-Recent Advances and Remaining Challenges for Lithium Ion Battery Cathodes. J. Electrochem. Soc. 2017, 164, A6341-A6348. [CrossRef]

16. Yang, Y.; Xiong, Y.; Zeng, R.; Lu, X.; Krumov, M.; Huang, X.; Xu, W.; Wang, H.; DiSalvo, F.J.; Brock, J.D.; et al. Operando Methods in Electrocatalysis. ACS Catal. 2021, 11, 1136-1178. [CrossRef]

17. Goodenough, J.B.; Park, K.-S. The Li-Ion Rechargeable Battery: A Perspective. J. Am. Chem. Soc. 2013, 135, 1167-1176. [CrossRef] [PubMed]

18. Armand, M.; Tarascon, J.M. Building better batteries. Nature 2008, 451, 652-657. [CrossRef]

19. Li, W.; Lutz, D.M.; Wang, L.; Takeuchi, K.J.; Marschilok, A.C.; Takeuchi, E.S. Peering into Batteries: Electrochemical Insight Through In Situ and Operando Methods over Multiple Length Scales. Joule 2021, 5, 77-88. [CrossRef]

20. Li, X.; Wang, H.-Y.; Yang, H.; Cai, W.; Liu, S.; Liu, B. In Situ/Operando Characterization Techniques to Probe the Electrochemical Reactions for Energy Conversion. Small Methods 2018, 2, 1700395. [CrossRef]

21. Gu, Q.; Kimpton, J.A.; Brand, H.E.A.; Wang, Z.; Chou, S. Solving Key Challenges in Battery Research Using In Situ Synchrotron and Neutron Techniques. Adv. Energy Mater. 2017, 7, 1602831. [CrossRef]

22. Harks, P.P.R.M.L.; Mulder, F.M.; Notten, P.H.L. In situ methods for Li-ion battery research: A review of recent developments. J. Power Sources 2015, 288, 92-105. [CrossRef]

23. Withers, P.J.; Bouman, C.; Carmignato, S.; Cnudde, V.; Grimaldi, D.; Hagen, C.K.; Maire, E.; Manley, M.; Du Plessis, A.; Stock, S.R. X-ray computed tomography. Nat. Rev. Methods Primers 2021, 1, 18. [CrossRef]

24. Carmignato, S.; Dewulf, W.; Leach, R. Industrial X-ray Computed Tomography, 1st ed.; Carmignato, S., Dewulf, W., Leach, R., Eds.; Springer: Berlin/Heidelberg, Germany, 2018; p. 369. [CrossRef]

25. Seeram, E. Computed Tomography: Physical Principles, Clinical Applications, and Quality Control, 4th ed.; Elsevier: Amsterdam, The Netherlands, 2015; p. 576. 
26. Deng, Z.; Lin, X.; Huang, Z.; Meng, J.; Zhong, Y.; Ma, G.; Zhou, Y.; Shen, Y.; Ding, H.; Huang, Y. Recent Progress on Advanced Imaging Techniques for Lithium-Ion Batteries. Adv. Energy Mater. 2021, 11, 2000806. [CrossRef]

27. Tang, F.; Wu, Z.; Yang, C.; Osenberg, M.; Hilger, A.; Dong, K.; Markötter, H.; Manke, I.; Sun, F.; Chen, L.; et al. Synchrotron X-Ray Tomography for Rechargeable Battery Research: Fundamentals, Setups and Applications. Small Methods 2021, 5, 2100557. [CrossRef]

28. Finegan, D.P.; Vamvakeros, A.; Cao, L.; Tan, C.; Heenan, T.M.M.; Daemi, S.R.; Jacques, S.D.M.; Beale, A.M.; Di Michiel, M.; Smith, K.; et al. Spatially Resolving Lithiation in Silicon-Graphite Composite Electrodes via in Situ High-Energy X-ray Diffraction Computed Tomography. Nano Lett. 2019, 19, 3811-3820. [CrossRef] [PubMed]

29. Sun, F.; Markötter, H.; Dong, K.; Manke, I.; Hilger, A.; Kardjilov, N.; Banhart, J. Investigation of failure mechanisms in silicon based half cells during the first cycle by micro X-ray tomography and radiography. J. Power Sources 2016, 321, 174-184. [CrossRef]

30. Wang, J.; Eng, C.; Chen-Wiegart, Y.-C.K.; Wang, J. Probing three-dimensional sodiation-desodiation equilibrium in sodium-ion batteries by in situ hard X-ray nanotomography. Nat. Commun. 2015, 6, 7496. [CrossRef]

31. Biemolt, J.; Jungbacker, P.; van Teijlingen, T.; Yan, N.; Rothenberg, G. Beyond Lithium-Based Batteries. Materials 2020, 13, 425. [CrossRef] [PubMed]

32. Maletti, S.; Sarapulova, A.; Tsirlin, A.A.; Oswald, S.; Fauth, F.; Giebeler, L.; Bramnik, N.N.; Ehrenberg, H.; Mikhailova, D Electrochemical behavior of LiV3O8 positive electrode in hybrid Li,Na-ion batteries. J. Power Sources 2018, 373, 1-10. [CrossRef]

33. Yuan, X.; Ma, F.; Zuo, L.; Wang, J.; Yu, N.; Chen, Y.; Zhu, Y.; Huang, Q.; Holze, R.; Wu, Y.; et al. Latest Advances in High-Voltage and High-Energy-Density Aqueous Rechargeable Batteries. Electrochem. Energy Rev. 2020, 4, 1-34. [CrossRef]

34. Gerasimova, L.G.; Nikolaev, A.I.; Shchukina, E.S.; Maslova, M.V. Titanite-Containing Mineral Compositions and Their Chemical Treatment with Preparation of Functional Materials. Materials 2020, 13, 1599. [CrossRef]

35. Shukaev, I.L.; Butova, V.V.; Chernenko, S.V.; Pospelov, A.A.; Shapovalov, V.V.; Guda, A.A.; Aboraia, A.M.; Zahran, H.Y.; Yahia, I.S.; Soldatov, A.V. New orthorhombic sodium iron(+2) titanate. Ceram. Int. 2020, 46, 4416-4422. [CrossRef]

36. Shapovalov, V.; Guda, A.; Butova, V.; Shukaev, I.; Soldatov, A. Laboratory operando xas study of sodium iron titanite cathode in the li-ion half-cell. Nanomaterials 2021, 11, 156. [CrossRef]

37. Kutukova, K.; Niese, S.; Gelb, J.; Dauskardt, R.; Zschech, E. A novel micro-double cantilever beam (micro-DCB) test in an X-ray microscope to study crack propagation in materials and structures. Mater. Today Commun. 2018, 16, 293-299. [CrossRef]

38. Kutukova, K.; Niese, S.; Sander, C.; Standke, Y.; Gluch, J.; Gall, M.; Zschech, E. A laboratory X-ray microscopy study of cracks in on-chip interconnect stacks of integrated circuits. Appl. Phys. Lett. 2018, 113, 091901. [CrossRef]

39. Schneider, C.A.; Rasband, W.S.; Eliceiri, K.W. NIH Image to ImageJ: 25 years of image analysis. Nat. Methods 2012, 9, 671-675. [CrossRef] [PubMed]

40. Topal, E.; Löffler, M.; Zschech, E. Deep Learning-based Inaccuracy Compensation in Reconstruction of High Resolution XCT Data. Sci. Rep. 2020, 10, 7682. [CrossRef]

41. Li, P.; Zhao, Y.; Shen, Y.; Bo, S.-H. Fracture behavior in battery materials. J. Phys. Energy 2020, 2, 022002. [CrossRef]

42. Feng, X.; Ren, D.; Zhang, S.; He, X.; Wang, L.; Ouyang, M. Influence of aging paths on the thermal runaway features of lithium-ion batteries in accelerating rate calorimetry tests. Int. J. Electrochem. Sci. 2019, 14, 44-58. [CrossRef]

43. Wei, C.; Zhang, Y.; Lee, S.-J.; Mu, L.; Liu, J.; Wang, C.; Yang, Y.; Doeff, M.; Pianetta, P.; Nordlund, D.; et al. Thermally driven mesoscale chemomechanical interplay in $\mathrm{Li}_{0.5} \mathrm{Ni}_{0.6} \mathrm{Mn}_{0.2} \mathrm{Co}_{0.2} \mathrm{O}_{2}$ cathode materials. J. Mater. Chem. A 2018, 6, $23055-23061$. [CrossRef]

44. Wang, H.; Jang, Y.I.; Huang, B.; Sadoway, D.R.; Chiang, Y.M. TEM Study of Electrochemical Cycling-Induced Damage and Disorder in $\mathrm{LiCoO}_{2}$ Cathodes for Rechargeable Lithium Batteries. J. Electrochem. Soc. 1999, 146, 473-480. [CrossRef]

45. Hu, Y.; Zhao, X.; Zhigang, S. Averting cracks caused by insertion reaction in lithium-ion batteries. J. Mater. Res. 2010, 25, 1007-1010. [CrossRef]

46. Xu, Z.; Rahman, M.M.; Mu, L.; Liu, Y.; Lin, F. Chemomechanical behaviors of layered cathode materials in alkali metal ion batteries. J. Mater. Chem. A 2018, 6, 21859-21884. [CrossRef]

47. Zhao, Y.; Xu, B.-X.; Stein, P.; Gross, D. Phase-field study of electrochemical reactions at exterior and interior interfaces in Li-ion battery electrode particles. Comput. Methods Appl. Mech. Eng. 2016, 312, 428-446. [CrossRef]

48. Xu, Z.; Jiang, Z.; Kuai, C.; Xu, R.; Qin, C.; Zhang, Y.; Rahman, M.M.; Wei, C.; Nordlund, D.; Sun, C.-J.; et al. Charge distribution guided by grain crystallographic orientations in polycrystalline battery materials. Nat. Commun. 2020, 11, 83. [CrossRef]

49. Pattammattel, A.; Tappero, R.; Ge, M.; Chu, Y.S.; Huang, X.; Gao, Y.; Yan, H. High-sensitivity nanoscale chemical imaging with hard x-ray nano-XANES. Sci. Adv. 2020, 6, eabb3615. [CrossRef] [PubMed]

50. Tan, X.; Jiang, K.; Zhai, S.; Zhou, J.; Wang, J.; Cadien, K.; Li, Z. X-ray Spectromicroscopy Investigation of Heterogeneous Sodiation in Hard Carbon Nanosheets with Vertically Oriented (002) Planes. Small 2021, 2102109. [CrossRef] [PubMed]

51. Zhang, J.; Wang, Q.; Li, S.; Jiang, Z.; Tan, S.; Wang, X.; Zhang, K.; Yuan, Q.; Lee, S.-J.; Titus, C.J.; et al. Depth-dependent valence stratification driven by oxygen redox in lithium-rich layered oxide. Nat. Commun. 2020, 11, 6342. [CrossRef]

52. Bak, S.-M.; Shadike, Z.; Lin, R.; Yu, X.; Yang, X.-Q. In situ/operando synchrotron-based X-ray techniques for lithium-ion battery research. NPG Asia Mater. 2018, 10, 563-580. [CrossRef]

53. Pelliccione, C.J.; Timofeeva, E.V.; Katsoudas, J.P.; Segre, C.U. Note: Sample chamber for in situ x-ray absorption spectroscopy studies of battery materials. Rev. Sci. Instrum. 2014, 85, 126108. [CrossRef] [PubMed] 
54. Sottmann, J.; Homs-Regojo, R.; Wragg, D.S.; Fjellvag, H.; Margadonna, S.; Emerich, H. Versatile electrochemical cell for Li/Na-ion batteries and high-throughput setup for combined operando X-ray diffraction and absorption spectroscopy. J. Appl. Crystallogr. 2016, 49, 1972-1981. [CrossRef]

55. Liu, Q.; He, H.; Li, Z.-F.; Liu, Y.; Ren, Y.; Lu, W.; Lu, J.; Stach, E.A.; Xie, J. Rate-Dependent, Li-Ion Insertion/Deinsertion Behavior of $\mathrm{LiFePO}_{4}$ Cathodes in Commercial $18650 \mathrm{LiFePO}_{4}$ Cells. ACS Appl. Mater. Interfaces 2014, 6, 3282-3289. [CrossRef]

56. Nakanishi, K.; Kato, D.; Arai, H.; Tanida, H.; Mori, T.; Orikasa, Y.; Uchimoto, Y.; Ohta, T.; Ogumi, Z. Novel spectro-electrochemical cell for in situ/operando observation of common composite electrode with liquid electrolyte by X-ray absorption spectroscopy in the tender X-ray region. Rev. Sci. Instrum. 2014, 85, 084103. [CrossRef] [PubMed]

57. Drozhzhin, O.A.; Tereshchenko, I.V.; Emerich, H.; Antipov, E.V.; Abakumov, A.M.; Chernyshov, D. An electrochemical cell with sapphire windows for operando synchrotron X-ray powder diffraction and spectroscopy studies of high-power and high-voltage electrodes for metal-ion batteries. J. Synchrotron Radiat. 2018, 25, 468-472. [CrossRef] [PubMed]

58. Borkiewicz, O.J.; Shyam, B.; Wiaderek, K.M.; Kurtz, C.; Chupas, P.J.; Chapman, K.W. The AMPIX electrochemical cell: A versatile apparatus for in situ X-ray scattering and spectroscopic measurements. J. Appl. Crystallogr. 2012, 45, 1261-1269. [CrossRef] 